\title{
EFFECT OF FEED ADDITIVES ON THE GUT MICROBIOTA VIS-A-VIS GROWTH, PRODUCTION AND CARCASS QUALITY OF FOOD ANIMALS
}

\author{
S. BISWAS ${ }^{1 *}$, O. BISWAS ${ }^{2}$, P. KANDASAMY ${ }^{2}$, S. PATNAIK $^{1}$, P. K. DAS ${ }^{3}$ \\ AND S. K. DAS ${ }^{4}$
}

\begin{abstract}
${ }^{1}$ Department of Livestock Products Technology, West Bengal University of Animal and Fishery Sciences, Kolkata- 700 037, West Bengal, India

${ }^{2}$ Department of Agricultural Engineering, Visva-Bharati, Santinikatan-731 235, West Bengal, India ${ }^{3}$ Department of Veterinary Physiology, West Bengal University of Animal and Fishery Sciences, Kolkata- 700 037, West Bengal, India

${ }^{4}$ Assistant Director (Research), West Bengal University of Animal and Fishery Sciences, Kolkata700 037, West Bengal, India
\end{abstract}

\begin{abstract}
Presence of numerous microorganisms in gut of the food animals, including aquatic fauna, is responsible for monitoring, maneuvering and modifying different physiological metabolic activities. This has a direct impact over growth and nutritional composition of body. Therefore the concern over gut microbiota is gaining more interest in the field of animal science research in recent days. It is more relevant with the fact that the world will face much more agricultural challenges in the coming decades to cater to the needs of protein diets for ever increasing global population. This study provides an overview of the efficacy of the feed additives to enhance nutrient utilization and production efficiency by altering gut microbial diversity where improved feed efficiency, modification of gut microbiota, effect of feed additives on dry matter intake and digestion, and effect of feed supplements on carcass quality and meat quality vis-à-vis gut microbiota.
\end{abstract}

Key words: Aquatic animal, Body weight growth, Carcass quality, Gut microbiota, Terrestrial animal.

\section{Introduction}

Gastro-intestinal tract of animals contains a variety of microorganisms which include bacteria, archea, protozoa and fungi, collectively called as gut microbiota and its genomes as gut microbiomes. Gut microbiota provides the host body with health benefits, aiding in digestion of nutrients, harvesting of energy, contributing to formation of the intestinal epithelial barrier, developing and functioning of immune system, and competing with the pathogenic microorganisms to prevent its harmful spread (Kogut and Arsenault, 2016). These microbes interact and initiate symbiotic relationships in the alimentary tract to hydrolyze the complex plant-based substances such as lignin, cellulose, hemicelluloses, xylan and pectin through active lignocellulolytic enzymes. These microbial population release enzymes, produce energy, volatile fatty acids [VFAsacetate, propionate, butyrate], formic acid, hydrogen, carbon-dioxide, and methane which can be used by the host for producing food 
products such as meat and milk (Krause et al., 2003). The healthy and active gut microbiome is dynamic and is influenced by diet, animal parameters, physiology, genetic and environmental effects in animals. In fish, the gut microbiota is affected by both, internal factors such as age, genetics, gender, nutrition, stress and external factors such as diet, quality of water and environment (Butt and Volkoff, 2019). The current review outlines the complex host-microbiota interactions on the development of animal production and aquaculture practices by reducing environmental impact has been ongoing for decades. Research using 'omic' technologies such as genomics, proteomics, transcriptomics, and metabolomics in the gut microbiomes has shown that the microbiome is a significant genetic resource, capable not only of improving the production level but also addressing global issues, including biofuel production, greenhouse gas reduction, the strengthening of food security, and increased global food supply (Kumar and Pitta, 2015).

A healthy and effective gut microbiota is essential for animal performance and achieving optimal productivity - it can be in producing milk, raising food animals, fish farming and growing to optimal weights, meat production and carcass quality. With the increasing pressure of growing population, there is a need to improve animal and aquaculture production by maintaining a healthy gut of animals and fish which can be achieved through the usage of different feed additives or supplements. However, various feed additives such as antibiotics, hormones, etc., pose a severe risk to the consumers, and are restricted to use in the host diet. Therefore, a variety of other important nutritional supplements such as probiotics, prebiotics, ionophore, essential oils, etc., are being tested to speed up the efficiency of animal production and also in aquaculture productivity.

\section{Improved feed efficiency: Gut microbiota}

With the rapidly growing need in global scenario, feed efficiency should be significantly improved. The most relevant production parameters in animals are the rate of growth and feed efficiency, which determine the processing of nutrients of feed into animal products. The rate at which food animals transform feed into desirable products is termed as feed conversion ratio (FCR) or feed conversion efficiency (FCE). Shike (2013) proposed another alternative to measure the efficacy of feed called as the residual feed intake (RFI), which is described as the variation between the actual diet and the expected diet depending upon the animal's body weight, weight gain, and composition. Assessing the feed conversion efficiency (FCE) of animals is a significant function of gut microbiota as they are responsible for converting nutrients into energy. Therefore, there is a relationship between the function of gut microbiota and feed efficiency and moreover, many factors affecting the feed efficiency such as age, diet, energy availability, also affect gut microbiomes. Bergamaschi et al. (2020) stated that the animals with lower FCE and lower RFI consume lesser amount of feed for each unit of body weight than expected and are considered as more efficient, while animals with higher FCE and higher RFI consume higher amount of feed for each unit of body weight than expected and are considered as less efficient. The use of high throughput sequencing experiments has shown that more efficient animals have low levels of microbial load (Shabat et al., 2016).

The rumen is a dynamic ecosystem where the nutrients consumed are digested and converted into edible meat and milk by fermentation of gut microbiota. Cellulose, which is digested by cellulolytic gut microbiota in the rumen, is the major constituent of plant feedstuff. A pH range between 6 and 9 is best ensured for the 
maintenance and development of cellulolytic bacteria such as Fibrobacter succinogens, Butyrivibrio fibrisolvens, Ruminococcialbus, and Clostridium lochheadii (Gonzalez et al., 2014). According to Weimer (1996), the involvement of extracellular enzymes, such as cellulase in the host, is involved in break down of B-glycosidic bonds in cellulose. The presence of certain forms of lipids in the diet and low $\mathrm{pH}(<5.5)$ decreases the mechanism of fiber digestion as this condition affects the development of cellulolytic bacteria (Krause and Denman, 2003). In feeds with lower concentrate portions and whole grains, starch is the main ingredient in diet which is degraded by the amylolytic bacteria. Streptococcus bovis degrades glucose to produce formate, acetate and ethanol when the host is fed with lesser amount of concentrates, but in the diets with more concentrates, S. bovis alters its metabolic processes and releases lactic acid leading a $\mathrm{pH}$ reduction to 5.5 which is harmful to the host animal (Russell and Hino, 1985). Therfore, other starch-reducing bacteria such as Bacteriodes ruminicola, Ruminobacter amylophilus, Selenomona sruminantium, Succinomonas amylolytica produce the VFAs such as formate, acetate, propionate and succinate. These VFAs are used as growth promoters to prevent metabolic imbalances (Cotta, 1992). Few bacteria such as Selenomonas lactilytica, Megasphaera elsdenii degrade lactate and control its accumulation to maintain a correct $\mathrm{pH}$ value (Mackie and Heath, 1979). According to Khafipour et al. (2016), ruminal acidosis is caused by a rise in the level of concentrates in the feed and indicates that Lactobacillus spp. and Streptococcus bovis are predominant in the rumen. Brown et al. (2006) stated that these microbial load increases when about $70 \%$ of the concentrate is fed to the animal. Bacteria that degrade pectin such as Butyrivibrio fibrisolvens, Provotella ruminicola, Bacteriodes ruminicola and Lachnospira multiparus release pectin lyases that digest pectin into oligogalacturonides (Duskova and Marounek, 2001).

Methane is the end product of fermentation of gut microbes and is known to be the complete wastage of energy consumed by the host, leading to the greenhouse effects (Garnsworthy et al., 2012). Methane is produced by carbon dioxide reduction by fermentation of methanogenic bacteria such as Methanobrevibacter ruminantium, Methanomicrobium mobile. The methanogenesis process is considered as a key factor for the removal of hydrogen ions from the rumen (Moss et al., 2000). Hook et al. (2012) stated that ruminal protozoa of Entodinomorphida and Holotricha orders retain feed contents and reduce the risk of ruminal acidosis in animals fed with a high concentration of digestible sugars. These fungi are favored by the consumption of highly concentrated fibrous forage and removed when incorporated with highly fermentable sugars. Consequently, the recognition of particular varieties of gut microbiota and its metabolic pathways, and alteration of gut microbiomes by promoting or minimising various processes provide opportunities for efficient feeding.

Fermentation of feedstuffs and nutrient absorption are known to be the main component of mechanism of digestion in fish alike the food animals. Various species of Acinetobacter, Areromonas, Flavo-bacterium, Lactococcus, Pseudomonas, Bacteriodes, Clostridium and Fusobacterium are predominantly found in freshwater aquatic animals. In marine fish, the alimentary tract consists of different species of Aeromonas, Alcaligenes, Alteromonas, Camobacterium, Flavo-bacterium, Micrococcus, Moraxella and Vibrio (Talwar et al., 2018). Research studies by Wu et al. (2012) on grass carp of genus Ctenopharyngodon supplemented with higher levels of cellulose in the diet has shown that the gastro-intestinal 
tract consists of different bacterial species such as Anoxybacillus, Actinomyces, Citrobacter, Clostridium and Leucostonoc. In zebra fish, Semova et al. (2012) noted that the intestinal microbiota influence the metabolism of fatty acid in the intestinal epithelium.

\section{Modification of gut microbiota}

Diversified gut microbial communities are associated with many host phenotypes such as efficiency of feed, methane production and disease status. Regulation of the gut environment and gut microbiota is a significant initiative in the animal production systems that can be accomplished by the introduction of various gastrointestinal modifiers or dietary supplements in the diet of the host animal. Pursuant to EU Regulation no. 1831 (2003), feed additives are specified as the products utilized in the feed of animals for the aim of improving the standard and the quality of foods of animal origin, or so as to enhance animal health and efficiency. There are different types of feed additives, which are broadly divided into nutrient supplements (amino acids, minerals and vitamins) and non nutrient supplements (probiotics, prebiotics, hormones, enzymes and antioxidants). These supplements are used to modify the gut microbial profile, the physiology of the host and the efficiency of the feed. Optimal levels of dietary supplements contribute to the increase in animal protein production and reduce the cost of animal products (Chahal et al., 2008).

Probiotics, also known as direct fed microbials (DFM) are defined as live cultures of noninvasive organisms that affect the host animal by improving gut microbial balance. Few probiotics commonly used in the feeds are Lactobacillus acidophilus, L. bifidus, L. casei, Streptococcus thermophilus, etc. They improve digestion of nutrients and also improve the utilization of animal feed effectively. Acoording to International Scientific Association of
Probiotics and Prebiotics (ISSAP), prebiotics are selective fermentable substances that lead to certain modifications in the structure or function of the gut microbiota and thus, have beneficial effects on the health of the host (Gibson et al., 2010). Prebiotics include polysaccharide carbohydrates such as starch and dietary fibre, proteins and lipids. Simultaneous use of probiotics and prebiotics is known as "synbiotics", - a coherent way to modify the microbial environment. Bomba et al. (2002) have shown a synergistic impact in reducing the number of pathogenic bacteria in food animals when fed with synbiotics. Throughout the digestive phase, enzymes such as amylases, cellulases, B-glucanases, phytases, pectinases, proteases and xylanases are used as feed additives to improve degrading reactions. Essential oils are used as supplements for antimethanogenic feed to maintain feed digestibility. Various herbal feed additives such as Asparagus racemosus, Cyathus stercoreus, Leptidenia reticulate, Phellinus linteus, etc. are added either individually or in combinations in the animal feed to increase gut microbial load and nutrients digestibility. However, these supplements should be given regularly, otherwise will create a negative impact once withdrawn from the feed (Wadhwa et al., 2016).

In aquaculture, the most regularly used probiotic and prebiotic are the genus Bacillus and mannanoligosaccharide, respectively. Other probiotics include the species of genus Aeromonas, Clostridium, Enterobacter, Enterococcus, Lactobacillus, Lactococcus, Leuconostoc, Pseudomonas, Vibrio, etc. They maintain the beneficial gut microbiota and improve the growth, immune system, and health of the host (Banerjee and Ray, 2017). Other prebiotics stimulating the growth of probiotics are inulin, fructooligosaccharides. Probiotic such as Lactobacillus spp. has been reported as growth promoter in turbot Scophthalmus maximus (Burr et al., 2005). Different research 
studies are being carried to produce lactic acid bacteria spp (LAB) with bactericidal properties to avoid the growth of pathogenic bacteria in the gut of fish (Catalan et al., 2017). Prebiotics such as organic acid salts and mannanoligosaccharides, fed in combinations, proved to enhance growth and health (Ringo et al., 2010). Feeding of synbiotics is a strategy to achieve more efficient fish growth, production and health (Cerezuela et al., 2011).

\section{Effect of feed additives on dry matter intake and digestion}

The effect on animal feed intake varies in quantity, quality of the various feed additives and the physical condition of the host animal. Cardozo et al. (2006) reported in their research that the result of feeding with a mixture of essential oils composed of cinnamaldehyde and eugenol, in beef cattle showed adverse effects on dietary intake. Yang et al. (2007) confirmed that there was no effect on the dry matter intake of feed additives when cattle were fed essential oils from garlic and juniper berry. Loor et al. (2004) reported that there is an improvement in the digestion process of animals fed with refined fats in combination with forage diets and a reversal is seen in concentrated diets. In animals, incorporated with a combination of Lactobacillus acidophilus and Propionibacterium, the average daily gain (ADG) was high but no changes in DM intake were observed by Swinney-Floyd et al. (1999). Similarly, Elam et al. (2003) and Brand et al. (2019) observed an increase in final weight, ADG, dietary DM and no significant differences in carcass characteristics in probiotic-feeding steers. Most in vivo studies in cattle have been conducted to report the effects of essential oils in growth and finishing phases of beef cattle using eugenol, hydroxycinnamic acid, and ferulic acid (Lourenco et al., 2008). Adverse effects were observed by Yang et al. (2010) when eugenol was added to the diet at high levels during the finishing phases of cattle.
Abdel and Ahmad (2009) reported that Spirulina, a probiotic in Nile tilapia, improved the FCR and also reported retention of nitrogen when fed with other probiotics. Mohapatra et al. (2012) reported that FCR decreased in rohu fingerlings when fed with probiotics. Askarian et al. (2012) noted that the LABs released different enzymes to improve the nutrient digestibility when fed with chitin in Atlantic salmon.

\section{Effect of feed supplements on carcass quality and meat quality}

Different parameters used to assess the quality of the carcass are carcass yield, commercial cuts, marbling, cut yield, lean yield, ribeye area, thickness of fat. In cattle, no differences in carcass quality and cut yields were observed when ferulic acid was given in feed according to a study by Meyer et al. (2009). GonzalezRios et al. (2016) noted that the dressing weight of the carcass increased following the addition of a mixture of essential oils and tylosin in the feed of steers. Chaves et al. (2011) and MaciasCruz et al. (2014) reported that there was no impact on carcass factors when sheep were fed with cinnamaldehyde and ferulic acid in the diet. Eshaghzadeh et al. (2014) reported that the inclusion of inulin $(10 \mathrm{~g} / \mathrm{kg})$ in the diets of common carp lowered the protein and lipid content of carcass. Supplementation of Bacillus subtilis in the fish diet improved the fat content but no improvement was seen in protein and moisture content (Allameh et al., 2017). The role of gut microbiota over CLA (Conjugated linoleic acid) synthesis is a matter of interest and investigation by the scientific community and identification of certain microbes had been done.

Kang et al. (2012) added quercetin (42 ppm) to cattle feed, and recorded an increase in water holding capacity (WHC) and meat $\mathrm{pH}$. Gonzalez-Rios et al. (2016) observed an improvement in tenderness, juiciness, and 
flavor when beef cattle were supplemented with ferulic acid for 30 days, while in sheep meat, Chaves et al. (2011) noted the off flavors when supplemented with hesperidin.

\section{Conclusion}

In the livestock sector, ensuring that the animals are healthy and in welfare, leads to improved animal performance, better growth and the production of high quality edible products such as milk, meat and fish. Central to the animal production system is the gut microbiome, which is an important contributor to the efficient production of phenotypes. Understanding the gut microbiome, its digestive processes, microbial strength, and the

\section{REFERENCES}

Abdel-Tawwab M and Ahmad MH, 2009. Live Spirulina (Arthrospira platensis) as a growth and immunity for Nile tilapia, Oreochromis niloticus (L.), challenged with pathogenic Aeromonas hydrophila. Aquac Res, 40(9): 1-10, doi: 10.1111/ j.1365-2109.2009.02195.x

Allameh SK, Noaman V and Nahavandi R, 2017. Effects of probiotic bacteria on fish performance. Adv Tech Clin Microbiol, 1(2:11): 1-5

Askarian F, Zhou Z, Olsen RE, Sperstad S and Ringo $\mathrm{E}, 2012$. Culturable autochthonous gut bacteria in Atlantic salmon (Salmo salar L.) fed diets with or without chitin: characetrization by $16 \mathrm{~S}$ rRNA gene sequencing, ability to produce enzymes and in vitro growth inhibition of four pathogens. Aquaculture, 326-329: 1-8, doi: 10.1016/ j.aquaculture.2011.10.016

Banerjee G and Ray AK, 2017. The advancement of probiotics research and its application in fish farming industries. Res Vet Sci, 115: 66-77, doi: 10.1016/j.rvsc.2017.01.016

Bergamaschi M, Tiezzi F, Howard J, Huang YJ, Gray KA et al., 2020. Gut microbiome composition differences among breeds impact feed efficiency in swine. Microbiome, 8: 110, doi: 10.1186/ s40168-020-00888-9

Bomba A, Nemcova R, Mudronova D and Guba P, 2002. The possibilities of potentiating the efficacy host microbial interactions by various molecular tools plays an important role in the performance and health of the animals. Therefore, the use of dietary supplements in animal and aquaculture feed is designed to alter the natural state of the gut and improve the utilization of animal nutrients, and thus cause less damage to the environment by reducing the release of harmful end products into the atmosphere. However, some feed additives can be harmful, if added in high doses. Therefore, the appropriate level of feed additives shoud be added to improve the level of performance, carcass characteristics and meat quality in terrestrial and aquatic animals.

of probiotics. Trends Food Sci Technol, 13(4): 121126, doi: 10.1016/S0924-2244(02)00129-2

Brand T, Hunerberg M, McAllister TA, He M, Saleem HA et al., 2019. Impact of a phytogenic feed additive on growth performance, feed intake, and carcass traits of finishing steers. Transl Anim Sci, 3(4): 1162-1172, doi: 10.1093/tas/txz109

Brown MS, Ponce CH and Pulikanti R, 2006. Adaptation of beef cattle to high-concentrate diets: performance and ruminal metabolism. J Anim Sci, 84(suppl): E25E33, doi: 10.2527/2006.8413_ supple25x

Burr G, Gatlin D and Ricke S, 2005. Microbial ecology of the gastrointestinal tract of fish and the potential application of prebiotics and probiotics in finfish aquaculture. J World Aquac Soc, 36(4): 425-436, doi: $10.1111 / \mathrm{j} .1749-7345.2005 . t b 00390 . x$

Butt RL and Volkoff H, 2019. Gut microbiota and energy homeostasis in fish. Front Endocrinol, 10: 9, doi: 10.3389/fendo.2019.00009

Cardozo PW, Calsamiglia S, Ferret A and Kamel C, 2006. Effects of alfalfa extract, anise, capsicum, and a mixture of cinnamaldehyde and eugenol on ruminal fermentation and protein degradation in beef heifers fed a high-concentrate diet. J Anim Sci, 84(10): 2801-2808, doi: 10.2527/jas.2005-593

Catalan N, Villasante A, Wacyk J, Ramirez C and Romero J, 2017. Fermented soybean meal increases 
lactic acid bacteria in gut microbiota of Atlantic salmon (Salmo salar). Probiotics Antimicrob Proteins, 10(3): 566-576, doi: 10.1007/s12602017-9366-7

Cerezuela R, Meseguer J and Esteban MA, 2011. Current knowledge in symbiotic use for fish aquaculture: A review. J Aquac Res Dev, S1: 008, doi: $10.4172 / 2155-9546 . S 1-008$

Chahal US, Niranjan PS and Kumar S, 2008. Handbook of General Animal Nutrition. International Book Distributing Co. India, pp2-292

Chaves AV, Dugan MER, Stanford K, Gibson LL, Bystrom JM et al., 2011. A dose-response of cinnamaldehyde supplementation on intake, ruminal fermentation, blood metabolites, growth performance, and carcass characteristics of growing lambs. Livest Sci, 141(2-3): 213-220, doi: 10.1016/ j.livsci.2011.06.006

Cotta MA, 1992. Interaction of ruminal bacteria in the production and utilization of maltooligosaccharides from starch. Appl Environ Microbiol, 58(1): 48-54

Duskova D and M Marounek, 2001. Fermentation of pectin and glucose, and activity of pectin degrading enzymes in the rumen bacterium Lachnospira multiparus. Lett Appl Microbiol, 33(2): 159-163, doi: $10.1046 /$ j.1472-765x.2001.00970.x

Elam NA, Gleghorn JF, Rivera JD, Galyean ML, Defoor PJ et al., 2003. Effects of live cultures of Lactobacillus acidophilus (strains NP45 and NP51) and Propionibacterium freudenreichii on performance, carcass, and intestinal characteristics, and Escherichia coli strain $\mathrm{O} 157$ shedding of finishing beef steers. J Anim Sci, 81(11): 26862698, doi: $10.2527 / 2003.81112686 x$

Eshaghzadeh $\mathrm{H}$, Hoseinifar SH, Vahabzadeh $\mathrm{H}$ and Ringo E, 2014. The effects of dietary inulin on growth performances, survival and digestive enzyme activities of common carp (Cyprinus carpio) fry. Aquac Nutr, 21(2): 242-247, doi: 10.1111/anu.12155

Garnsworthy PC, Craigon J, Hernandez-Medrano JH and Saunders N, 2012. On-farm methane measurements during milking correlate with total methane production by individual dairy cows. J Dairy Sci, 95: 3166-3180, doi: $10.3168 /$ jds.2011-4605
Gibson GR, Scott KP, Rastall RA, Tuohy KM, Hotchkiss A et al., 2010. Dietary prebiotics: current status and new definition. Food Sci Tech Bull: Func Foods, 7 (1): 1-19, doi: 10.1616/14762137.15880

Gonzalez ARC, Burrola-Barrazab ME, DominguezViverosb J and Chavez-Martinez A, 2014. Rumen microorganisms and fermentation. Arch Med Vet, 46(3): 349-361, doi: 10.4067/S0301$732 \mathrm{X} 2014000300003$

Gonzalez-Rios H, Davila-Ramirez JL, Pena-Ramos EA, Valenzuela-Melendres M, Zamorano-Garcia L et al., 2016. Dietary supplementation of ferulic acid to steers under commercial feedlot feeding conditions improves meat quality and shelf life. Anim Feed Sci Technol, 222: 111-121, doi: 10.1016/j.anifeedsci.2016.10.011

Hook SE, Dijsktra J, Wright ADG, McBride BW and France J, 2012. Modeling the distribution of ciliate protozoa in the reticulo-rumen using linear programming. J Dairy Sci, 95(1): 255-265, doi: $10.3168 /$ jds.2011-4352

Kang M, Kim HJ, Jang A, Gam DK, Yun GS et al., 2012. Effect of dietary supplentation of quercetin on antioxidant activity and meat quality of beef cattle. CNU J Agric Sci, 39(1): 61-68

Khafipour E, Li S, Tun HM, Derakhshani H, Moossavi S et al., 2016. Effects of grain feeding on microbiota in the digestive tract of cattle. Anim Front, 6(2): 13-19, doi: 10.2527/af.2016-0018

Kogut MH and Arsenault RJ, 2016. Gut health: the new paradigm in food animal production. Front Vet Sci, 3: 71, doi: 10.3389/fvets.2016.00071

Krause DO, Denman SE, Mackie RI, Morrison M, Rae AL et al., 2003. Opportunities to improve fibre degradation in the rumen: microbiology, ecology, and genomics. FEMS Microbiol Rev, 27: 663-693, doi: 10.1016/S0168-6445(03)00072-X

Kumar S and Pitta DW, 2015. Revolution in Rumen Microbiology. In Rumen Microbiology: From Evolution to Revolution, A.K. Puniya et al. (eds.), Springer, India, pp357-379, doi: 10.1007/978-81322-2401-3_24

Loor JJ, Ueda K, Ferlay A, Chilliard Y and Dorean M, 2004. Biohydrogenation, duodenal flow, intestinal 
digestibility, of trans fatty acid and conjugated linoleic acids in response to forage: concentrate ratio and linseed oil in dairy cows. J Dairy Sci, 87(8): 2472-2485, doi: $10.3168 /$ jds.S00220302(04)73372-X

Lourenco M, Cardozo PW, Calsamiglia S and Fievez V, 2008. Effects of saponins, quercetin, eugenol, and cinnamaldehyde on fatty acid biohydrogenation of forage polyunsaturated fatty acids in dual-flow continuous culture fermenters. J Anim Sci, 86(11): 3045-3053, doi: 10.2527/jas.2007-0708

Macias-Cruz U, Perard S, Vicente R, Alvarez FD, Torrentera-Olivera NG et al., 2014. Effects of free ferulic acid on productive performance, blood metabolites, and carcass characteristics of feedlot finishing ewe lambs. J Anim Sci, 92(12): 5762-5768, doi: $10.2527 /$ jas.2014-8208

Mackie RI and S Heath, 1979. Enumeration and isolation of lactate-utilizing bacteria from rumen of sheep. Appl Environ Microbiol, 38(3): 416-421

Meyer NF, Erickson GE, Klopfenstein TJ, Greenquist MA, Luebbe MK et al., 2009. Effect of essential oils, tylosin, and monensin on finishing steer performance, carcass characteristics, liver abscesses, ruminal fermentation, and digestibility. J Anim Sci, 87(7): 2346-2354, doi: 10.2527/jas.2008-1493

Mohapatra S, Chakraborty T, Prusty AK, Das P, Paniprasad K et al., 2012. Use of different microbial probiotics in the diet of Rohu, Labeo rohita fingerling: effects on growth, nutrient digestibility and retention, digestive enzyme activities and intestinal microflora. Aquacult Nutr, 18: 1-11, doi: 10.1111/j.1365-2095.2011.00866.x

Moss AR, Jouany JP and Newbold J, 2000. Methane production by ruminants: its contribution to global warming. Ann Zootech, 49: 231-253, doi: 10.1051/ animres:2000119

Ringo E, Olsen RE, Gifstad TO, Dalmo RA, Amlund H et al., 2010. Prebiotics in aquaculture: A review. Aquacult Nutr, 16(2): 117-136, doi: 10.1111/ j.1365-2095.2009.00731.x

Russell JR and Hino T, 1985. Regulation of lactate production in Streptococcus bovis: A spiraling effect that contributes to rumen acidosis. J Dairy Sci, 68(7): 1712-1721, doi: 10.3168/jds.S00220302(85)81017-1
Semova I, Carten JD, Stombaugh J, Mackey LC, Knight $\mathrm{R}$ et al., 2012. Microbiota regulate intestinal absorption and metabolism of fatty acids in the zebrafish. Cell Host Microbe, 12(3): 277-288, doi: 10.1016/j.chom.2012.08.003

Shabat SKB, Sasson G, Doron-Faigenboim A, Durman T, Yaacoby S et al., 2016. Specific microbiomedependent mechanisms underlie the energy harvest efficiency of ruminants. ISME J, 10(12): 2958-2972, doi: $10.1038 /$ ismej.2016.62

Shike DW, 2013. Beef Cattle Feed Efficiency. Driftless Region Beef Conference Proceedings: https:// lib.dr.iastate.edu/driftlessconference/2013/papers/ 13/ [15 September 2020]

Swinney-Floyd D, Gardner BA, Owens FN, Rehberger T and Parott T, 1999. Effect of inoculation with either strain P-63 alone or in combination with Lactobacillus acidophilus LA53545 on performance of feedlot cattle. J Anim Sci, 77(Suppl 1): 77

Talwar C, Nagar S, Lal R and Negi RK, 2018. Fish gut microbiome: current approaches and future perspectives. Indian J Microbiol, 58(4): 397-414, doi: 10.1007/s12088-018-0760-y

Wadhwa M, Bakshi MPS and Makkar HPS, 2016. Modifying gut microbiomes in large ruminants: opportunities in non-intensive husbandry systems. Anim Front, 6(2): 27-36, doi: 10.2527/af.2016-0020

Weimer PJ, 1996. Why don't ruminal bacteria digest cellulose faster? J Dairy Sci, 79(8): 1496-1502, doi: 10.3168/jds.S0022-0302(96)76509-8

Wu S, Wang G, Angert ER, Wang W, Li W et al., 2012. Composition, diversity, and origin of the bacterial community in grass carp intestine, PLoS One, 7(2): e30440, doi: 10.1371/journal.pone.0030440

Yang WZ, Benchaar C, Ametaj BN and Beauchemin KA, 2010. Dose response to eugenol supplementation in growing beef cattle: ruminal fermentation and intestinal digestion. Anim Feed Sci Technol, 158(1-2): 57-64, doi: 10.1016/ j.anifeedsci.2010.03.019

Yang WZ, Benchar C, Ametaj BN, Chaves AV, He ME et al., 2007. Effects of garlic and juniper berry essential oils on ruminal fermentation and on the site and extent of digestion in lactating cows. J Dairy Sci, 90(12): 5671-5681, doi: 10.3168/ jds.2007-0369

Received-23.09.2020, Accepted-03.11.20 Published-01.12.2020 